\title{
Guidelines for the admissibility of farm and catchment models in the New Zealand environment courts
}

\author{
$\underline{\text { A. Parshotam }}^{\text {a }}$ \\ ${ }^{a}$ LERNZ (Lake Ecosystem Restoration New Zealand), Environment Research Institute, The University of \\ Waikato, New Zealand \\ Email: aroonp@waikato.ac.nz
}

\begin{abstract}
Mathematical and computer models are useful as environment policy tools in environmental management, and appear everywhere from climate science to economic impact assessments. Because modelling tools are useful for determining environmental policy, this also means that internationally, mathematical scientists are increasingly entering debates concerning environmental policy. As a result, courts are becoming a public forum for scientific debate. Models are being used more and more in legally binding international protocols and environmental reporting, to the point where some models are prescribed as standards that all countries must adopt. This paper discusses some concerns regarding use of catchment and farm systems models in the environment court. The OVERSEER $\AA$ nutrient budget model, as a case in point, is used as compliance tool and by councils to assess impacts in specific resource consent application processes. It is also a model used widely as a sub-model in several New Zealand catchment models, such as CLUES. It is probably the only model used in New Zealand for regulatory purposes.

This paper explores the qualities a model must have for regulatory purposes, in order to be admissible in the legal arena. Daubert standards, used to assist courts overseas in assessing the admissibility of scientific evidence, are explored for their relevance to scientific modelling. These standards, or a variant, could present one way forward out of the current quagmire.
\end{abstract}

Daubert standards for a theory or technique are related to:

1) Testability: whether the theory or technique is falsifiable, refutable, and/or testable,

2) Peer review: whether it has been subjected to peer review and publication,

3) Uncertainty: the known or potential error rate,

4) Protocols: the existence and maintenance of standards and controls concerning its operation, and

5) Acceptance: the degree to which the theory and technique is generally accepted by a relevant scientific community.

Models such as OVERSEER $®$ are tested to see if they meet the above criteria. This work is of great importance for progress within the farm systems and catchment modelling sector in New Zealand.

Keywords: Farm models, catchment models, admissibility, environment courts, Daubert standards 
A. Parshotam, Guidelines for the admissibility of farm and catchment models in the New Zealand environment courts

\section{INTRODUCTION}

Mathematical and computer models are sometimes extremely useful tools in the courts. Just as physical models might be useful to describe the details of a car accident, environmental models, for example, might be useful to describe changes resulting from proposed land use changes. Often there is little data on which to base decisions, which leads to a great reliance on models. In this context, mathematicians are increasingly being called to appear as expert witnesses. This phenomenon is occurring internationally, with courts often becoming a public forum for scientific debate as a result. Such debates may even revolve around the values of single parameters (Graeme Wake, pers. comm., in relation to an insurance claim).

The courts have a difficulty with "unsettled" science (Forrett, 1998). Science generally brings its own set of unsettled issues and environment court judges have their own understanding of science. The same holds true for mathematical modelling: world ranking classically trained applied mathematicians would say that a mathematical model with more than five variables is a model with too many variables and one cannot see the wood for the trees, whereas other mathematicians would quite comfortably work with system dynamics models which allow for the interaction of a large number of variables within a system. It is said that there is no science without numbers - you cannot have science without measurement. Mathematical modelling has changed the sciences and possibly every other discipline in either an indirect or a direct way. There are no rules to mathematical modelling; some guidelines perhaps, but a lot depends on 'training'. There is sometimes a perception that all models are wrong but some are more wrong - models are to be believed but not trusted.

In New Zealand, scientific expertise is included in the local authority planning process to provide appropriate guidelines and rules for district and regional plans. Mathematical models are often useful to produce these guidelines from fundamental environmental science research. These guidelines can relate to catchment water quality, discharge, contaminants and noise levels for example. Modelling also features in the resource consent process, where applicants are required to provide an assessment of the likely environmental impacts from the proposed activity. Environmental impacts assessments are therefore increasingly being provided by experts in science, planning and engineering, to mention a few areas, and mathematical models are increasingly being used for prediction. Modelling also enters into the litigation arena, more directly as expert testimony. This testimony may be founded on proven scientific theories in courts which can not only be involved with making decisions but can in fact become a forum for public debate on mathematical modelling methods. At one time, in the 1980s it was difficult to convince researches of the importance of catchment modelling but today it is difficult to convince them otherwise (Graham McBride, pers comm.).

Mathematical and computer models are useful as policy development tools in environmental management and appear everywhere from climate science to economic impact assessment. Modelling concepts such as ecological footprints, carbon and nutrient trading, greenhouse accounting, and sea level rise are now commonplace. The IPCC assessment reports and the Stern report on the economics of climate change are summaries of model outputs. Mathematical modelling tools give scientific credence - we used a model. Mathematical models are useful for determining environmental policy and this also means that internationally, mathematical scientists are entering debates concerning environmental policy. Models are being used more and more for legally binding international protocols and environmental reporting, to the point where some models are standardized for all countries to adopt - we have a lot of faith in our models. Karl Popper, perhaps the greatest philosopher of science in the last century, argued that society works best when it is open - open that is to critical discussion and debate. This avoids ideology and the crystallisation of knowledge: in the words of the philosopher Hume, "the mind has a tendency towards dogma". If we want useful models of the world, our models should not be allowed to become dogmas and have a 'life' of their own.

In a recent unpublished study by the author, examples were collated of scientific models presented in the New Zealand environment courts. These models illustrated the current 'culture' that exists regarding the use and admissibility of models, and related pitfalls, in New Zealand. The case studies included pollutant discharges, hydrogeology, groundwater flow, groundwater resources, and irrigation in a catchment. It was shown that there does not appear to any attempt of legal standards in New Zealand for admissibility of expert testimony involving mathematical modelling. The expert witness narrative is usually "My name is X. I am an expert modeller with 20 years of experience in modelling and I know what I am talking about." No one has the patience to investigate a large complex model with its numerous variables. Models are often developed inhouse by individuals with the underlying assumptions not being generally open to debate with the excuse of reasons of commercially sensitivity. We are in a quagmire and it is necessary that we find a way to move forward. It was suggested by the author in this study that Daubert standards, used to assist courts overseas in assessing admissibility of scientific evidence, should be explored for their relevance to mathematical and scientific modelling, and that these standards or variants of these standards could present one way forward. 

courts

This paper discusses some concerns in the current state of affairs regarding use of catchment and farm systems modelling in a legal setting. It highlights some issues that arise when mathematical models are used for policy. The OVERSEER $\AA$ nutrient budget model (hereafter referred to as OVERSEER) (Wheeler et al., 2006) as a case in point, is undoubtedly the most widely used farm nutrient model in New Zealand. It is used as compliance tool and by councils to assess effects in specific resource consent applications. It is also used within catchment models such as CLUES (Woods et al., 2006). Models such as OVERSEER have not to date been challenged in the environment courts as a (mathematical) model but some of the underlying scientific processes of the model have been discussed in the environment courts. This paper discusses the qualities a model must have in order to be admissible in the environment courts.

\section{REVIEW}

Coupled models linking two different models used by government agencies to inform policy development, have been linked together to model the future at a national scale - one a model of land use change and the other a model to estimate nutrient loads in water (e.g. Parshotam et a., 2013). These have shed some light on the direction in which the quality of fresh water might be heading in different parts of New Zealand (Parshotam et al., 2013; Parliamentary Commissioner for the Environment, 2013).

The National Policy Statement on Freshwater Management 2014 (NPS-FM 2014) and the Resource Management Act 1991 (RMA), provide the framework within which regional councils set regional policy statements and regional plan objectives to manage the effects of land use practices on water quality and quantity. The New Zealand Resource Management Act (RMA) requires that applications for resource consent should contain an assessment of the effects on the environment. These assessments are often informed by simulation model runs, with scientific and economic assumptions.

\subsection{Catchment and farm systems models}

As well as regional authorities, catchment and farm systems modelling has become a standard tool used by catchment (and farm) managers for catchment management. These models are used for various purposes including: 1) research, 2) farm-level consulting, 3) to inform policy design and, 4) as a compliance tool. The models used could be simple, empirically-based, land-use export-coefficient models or highly complex dynamic, physically-based, semi-mechanistic models incorporating information on slopes, rainfall, soil types, land-uses, vegetation, and land management practices and a good understanding of farm systems, including stocking rates and fertilizer application rates and irrigation. Conceptually, catchment water quality models range in complexity from parsimonious, few-parameter empirical models, through to more detailed lumped, then distributed, multi-parameter conceptual models, to complex multi parameter physically-based distributed models (Adams, 2007). Generally, however, modelling for catchment management may be divided into two categories: 1) farm or paddock scale nutrient models that provide estimates of nutrient loss, and, 2) catchment scale nutrient models that consider how nutrients and sediment travel across catchments to water bodies. Catchment models consider both urban and rural contexts and in a rural context need well-formulated and 'transparent' farm scale models.

Several catchment scale nutrient models (e.g. CLUES) are being used by Regional Councils and unitary authorities for catchment management and to inform policy development. The range of models used in New Zealand is often a response to the range of questions that models are expected to answer, and the range of contexts in which models are used. A report discussing water quality modelling for an audience unfamiliar with the practice is given by Anastasiadis et al. (2013) in a New Zealand context. An overview of models such as of ROTAN, AquiferSim, CLUES, MODFLOW, FEMWATER in New Zealand is given in Fenton (2009). Compiled inventories of the various decision support models used in New Zealand, the interactions between models and associated case studies are given on the Envirolink website at http://tools.envirolink.govt.nz/dsss. Descriptions of the models OVERSEER and SPASMO as well as the APSIM model developed in Australia used in New Zealand are given in Appendix E of Benson (2012). There have been comparisons of OVERSEER model output with other models such as SPASMO (MacKay, et al. 2012) and APSIM (Vibart et al. 2015). Descriptions of all these models may consider model inputs and computer requirements, but do not generally consider model formulation. In relation to OVERSEER, it is believed that modelling (and measuring) any biological system will be subject to error but some of these errors cancel out when one model output is compared with one another (Williams et al., 2014).

The OVERSEER ${ }^{\circledR}$ Nutrient Budgeting Model, is widely used throughout New Zealand, by fertiliser company representatives, farmers, farm consultants and Regional Councils. OVERSEER is an agricultural management tool to assist farmers and their advisers to examine nutrient use and movements within a farm in order to optimise production and environmental outcomes. OVERSEER works at the whole-farm scale and is freely available. A cut-down version of OVERSEER has been incorporated into catchment models such as CLUES 

courts

and ROTAN. OVERSEER was initially developed to advise farmers on fertilizer application but is today used as a compliance tool in a regulatory environment. The dairy industry is using OVERSEER as a tool to assist their farmer's benchmark themselves against others in their sustainability accord. This will require that all farmers record enough information to allow an up to date overseer file to be completed for their farms. OVERSEER is the most appropriate tool to be used by both regulators and the pastoral industry to manage land use within environmental constraints, as it gives the comparative risks of a management activity to the receiving environment - without OVERSEER, farmers would be facing a regime of "input controls" in order to minimise their effects on the environment (Dewes, 2013).

Regional councils such as Environment Waikato uses OVERSEER to calculate Nitrogen Discharge Allowances for Lake Taupo farmers. Similarly, Bay of Plenty Regional Council is using OVERSEER to benchmark Rotorua farmers under its 'Rule 11', which puts a cap on the amount of nitrogen and phosphorus that can leave a farm (Park, 2014). Under the Canterbury Land and Water Regional Plan, farmers are expected to use OVERSEER to calculate how much nitrogen will leach from their farms into groundwater. Other Regional Councils use OVERSEER to assess impacts in specific resource consent applications. Ledgard (2009) was of the opinion that OVERSEER is based on sound scientific principles and validated against New Zealand field measurement. Clothier (2008) was of the opinion that OVERSEER was the most appropriate model for use in the Lake Taupo catchment. OVERSEER is the obvious choice for estimating nutrient losses from pastoral farms according to Monoghan (2010). OVERSEER was accepted by the industry representatives on the Matrix of Good Management (MGM) project to identify expected nutrient losses under good management practices as the best tool available to assess nutrient losses (Williams et al., 2014). There are numerous debates reported in the media about model output from the various versions of the model. Tests of model performance and the costs of misinformation to farmers using various versions of the model are given by Dewes (2015). There are published statements on accuracy of OVERSEER and known limitations (http://overseeer.org.nz/how-accurage-is-overseer). The challenges for councils are 1) how to deal with model version changes, 2) managing input data quality and auditing, 3) setting user requirements, 4) understanding the model averaging methods, 5) understanding the level of uncertainty in the modelled outputs and 6) getting more calibration data sets. One important benefit of OVERSEER is the default farm information databases it includes. Apart from internal reports and numerous conference presentations, there is very little published on OVERSEER in the peer reviewed journals, some model application papers but nothing published on the formulation of the model. There has been some recent releases of single-author technical reports on OVERSEER at http://overseer.org.nz/technical-information where components of the model is are still referred to as 'black boxes', i.e. as a mathematical model, it is still a black box. The source code is not available for commercially sensitive reasons (Caroline Read, pers comm). The model has not been challenged yet, as a model (formulation, algorithms, etc.), in the environment courts. OVERSEER is probably the only model used in New Zealand for regulatory purposes and it raises the following question "How can a model developed inhouse by (single) individuals be used for regulatory purposes, nationally?"

\subsection{Model transparency}

Model transparency is much more than a release of computer code. Model transparency should mean the availability of computer source code and the availability of mathematical formulation, algorithms and assumptions. Models used in regulation require significantly more validation than models for non-regulatory purposes but what are we parameterizing and validating? Unless there is more openness with code and formulation, progress will be stalled and alternative potentially useful models will be developed such as the farm systems model, AgSoft (Graeme Wake, pers. comm., Doug Edmeades pers. comm) which is a dynamic model which calculates the economic outcome from any chosen fertilizer on a given farm. Powerful catchment models such as SWAT (http://swat.tamu.edu/) developed in the United States with its international community of developers and INCA developed in the United Kingdom are being adopted in New Zealand for reasons of openness. More rigorously founded models developed overseas are often not available or suitable for application in New Zealand. A lot of other models too have a similar lack of transparency (e.g. source code to CAEDYM is now not readily available).

\subsection{Model parameterisation}

Some of the most widely used catchment models (or their derivatives) may have built into them thousands of parameter files, each with thousands of parameters assumed (e.g. GLEAMS (Parshotam et al. (2009)). These 'descriptive', essay-like models may be coupled to ecological lake models such as CAEDYM with (at least) 400 parameters (Hamilton, pers. comm.) or estuary models, or form part of much larger integrated catchment models (ICMs) which couple catchment biophysical models with socio-economic models. Computer models do demonstrate that "computers have taken us a long way". Much discussion is around the computer code and what is being included in the model rather than the basic assumptions of the model and its formulation. As 

courts

such, the whole modelling process becomes one of inverting the process of scientific discovery. A model as a re-presentation of reality should be an extended set of hypotheses, to be tested against reality for it to be scientific.

Parameter values are chosen from the range given in the literature and earliest references of parameter values seem to be arbitrary. Relationships between parameters are not normally considered. The process of manually adjusting or 'tweaking' parameter values based on human judgement is a leap of faith and another leap of faith is considering a subsystem of the model for scenario testing using parameters estimated from the whole system - with so very little data to calibrate a model, one can quite easily overestimate the effects of land-use which can have a tremendous effect when a scenario involving a subsystem of land-use change is being tested. Often measurement data is not available and if the model is physically based, it may not even be needed. In practice, model error statistics and goodness of fit for model calibration and validation does not usually take into account the number of parameters assumed in the model, as it should do with an adjusted $\mathrm{R}^{2}$ to take into consideration the number of predictors in multiple regression, for example. Rather, model performance is determined by correlating model output to observed values. Model calibration (the science of testing various parameter values against a simulated reality) is an extremely time consuming process of manually adjusting selected parameters (intelligently and foolishly) until a good fit is observed visually (an art). The problem with complex models is how to deal with parameterisation of parameters that are unavailable or difficult to measure. And if you do decide to measure them comprehensively, by the time you have done that you know the system so well you don't need a model (Luke Mosley, pers comm). One key issue with complex multi-parameter models is that there is likely not to be one unique parameter set that the model may show good performance statistics on. Hence, model performance statistics may not give a true representation of model accuracy (Arhonditsis and Brett, 2004; Bennett et al., 2013).

One is reminded of the applied mathematician Gauss who stated "Give me five parameters and I shall fit you an elephant". This statement is synonymous with "garbage in garbage out" or "you can fit anything" (Graeme Wake, pers comm). In spite of this, most environmental systems models with large numbers of parameters nevertheless have a very difficult time getting a good fit to the data, and researchers are therefore often forced to accept a rather poor calibration. Modelling should capture and explain bits of a system and with such models, one cannot see the wood for the trees (Graeme Wake, pers comm.). The best computer is the one between your ears (Graeme Wake, pers comm.) something both statisticians and mathematicians do agree on. If such models are challenged in an environment court, it is important to at least be able to say that a Genetic algorithm was used for parameter estimation to remove the human factor (Kit Rutherford, pers comm.). Currently, complex simulation models with large input requirements would not stand up in an environment court.

\section{DISCUSSION}

There are therefore many issues and pitfalls involved in the current state of affairs admitting farm and catchment models in the environment courts. The question is how are some of these issues dealt with internationally and how can some of these problems be resolved in the New Zealand environment courts? There are no 'rules' for modelling applied to the spectrum of models. Specific guidelines for New Zealand catchments on defensible modelling could be useful (e.g. Australian groundwater modelling guidelines by Merz, et al., (2012)). There is currently nothing to provide the information that New Zealand RMA lawyers need to know about catchment and farm systems modelling, specifically, and this information is necessary. Policy has dragged modelling into the legal arena; one approach for managing the admissibility of mathematical models in the Environment courts is that they should satisfy the Daubert standard's summarized below. Complex systems modelling under Daubert standards is discussed by Stephens et al. (2005) and summarised below.

\subsection{The Daubert Standards}

The most visible sign of the integration of science and law was the US Supreme Court's decision in Daubert v. Merrell Dow Pharmaceuticals, Inc. (1993). The Court for the first time in its history, considered the standard for evaluating the admissibility of scientific expert testimony. Application of the Daubert standard requires an understanding of scientific research. Daubert and related rulings oblige the trial court to be the evidentiary "gate-keeper" who screens proffered expert testimony for admissibility. Daubert made an explicit link between the reliability of an expert's testimony and the expert's use of scientific knowledge derived by the scientific method:

...the subject of an expert's testimony must be scientific...knowledge...[it is] the requirement that an expert's testimony pertain to "scientific knowledge".... [that] establishes a standard of evidentiary reliability.

In order to qualify as "scientific knowledge", an inference or assertion must be derived by the scientific method. Scientific methodology today is based on generating hypotheses and testing them to see if they can be falsified; indeed, this methodology is what distinguishes science from other fields of human inquiry. 
A. Parshotam, Guidelines for the admissibility of farm and catchment models in the New Zealand environment courts

The decision in Daubert identified four factors that could assist courts in assessing admissibility of scientific evidence. These are summarized by Forrett (1998): 1) the degree of testing which the theory or technique has undergone, 2) the extent of peer review and the publication of the theory or technique, 3) the known or potential margin of error for a particular technique together with its methodological reliability, and 4) the level of general acceptance of the theory or technique within the relevant scientific community. Based on the scientific method, Daubert and associated rulings provided criteria for trial courts to use in evaluating the scientific validity and resulting evidentiary reliability and admissibility of expert testimony. In essence it stated that the Law has to work towards accepting the scientific method.

\subsection{How mathematical modelling can satisfy the Daubert standards}

It does not appear that, internationally, mathematical modelling has yet faced an admissibility challenge under the Daubert rulings. These rulings would require that mathematical modelling be subject to the scientific method. Table 1 presents an interesting set of criteria and sub-criteria in relation to dynamical systems modelling for expert witness testimony under Daubert summarized from Stephens et al. (2005).

Table 1. Criteria and sub-criteria for expert witness under Daubert, from Stephens et al. (2005).

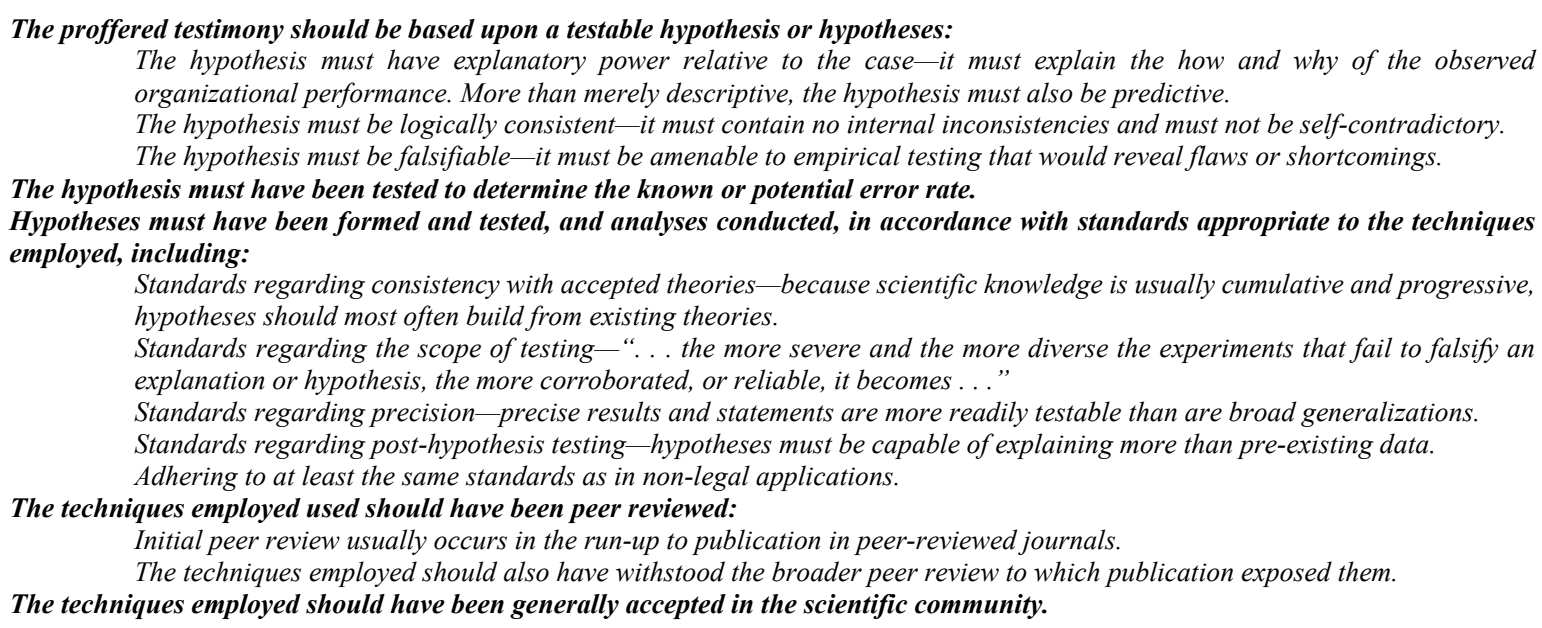

Currently, it does not appear that many catchment or farm systems models (such as OVERSEER) in New Zealand would pass a Daubert admissiability test. This may be simply because of the lack of openness and transparency and the peer review processes expected. This can change for the better. Modelling guidelines need to be encouraged. The pros and cons of adopting Daubert standards or a variant of it will be required.

\section{CONCLUSIONS AND RECOMMENDATIONS}

It is rather ironic that the courts have become the public forum for scientific debate involving scientific models and we can learn from these both from a New Zealand and an international perspective. What is proposed in this paper is not the way forward but $a$ way forward. Modelling is evolving and does not follow strict rules and that is the last thing modellers need. Guidelines have been presented in this paper for the admissibility of catchment and farm systems models in the environment courts. At this stage one cannot expect many models to adhere to these standards. There however, needs to be more openness, transparency and discussion about the process of modelling and modelling assumptions before there can be dialogue. The guidelines presented here form the basis of more general (and less stringent) guidelines being formulated by the author.

A pluralism of models is needed; expensive as it may be in the short term. A spectrum of farm system and catchment model output such as that found in climate change models with their various emissions scenarios could be encouraged. Models designed in-house by individual(s) should not be used nationally for policy, despite expert judgement. In New Zealand, this has arisen out of the culture of institutional science and because New Zealand is rather small. Furthermore, more rigorously founded models developed overseas are often not available or suitable for application in New Zealand.

\section{ACKNOWLEDGMENTS}

The author would like to thank Professor Barry Barton, University of Waikato, for supervising the project as part of postgraduate degree in environmental law. 
A. Parshotam, Guidelines for the admissibility of farm and catchment models in the New Zealand environment courts

\section{REFERENCES}

Adams, G.A. (2007). Towards an Effective Complexity for Modelling Nutrient Generation from Small Catchments. Interational In Oxley, L. and Kulasiri, D. (eds) International Congress on Modelling and Simulation. Modelling and Simulation Society of Australia and New Zealand, December 2007.

Anastasiadis, S., Kerr, S., Arbuckle, C., Elliott, W., Hadfield, J., Keenan, B., McDowell, R., Webb T. and R. Williams. (2013). Understanding the Practice of Water Quality Modelling, Motu Economic and Public Policy Research, Wellington.

Arhonditsis, G.B. and M.T. Brett (2004). Evaluation of the current state of mechanistic aquatic biogeochemical modelling. Mar Ecol Prog Ser. 271: 13-26.

Bennett, N.D., Croke, B.F.W., Buariso, G., Guillaume, J.H.A., Hamilton, S.H., Jakeman, AnJ., Marsili-Libeli, S., Newham, L.T.H., Norton, J.P., Perrin, C., Peirce, S.A., Robson, B., Seppelt, R., Voinov, A.A., Fath, B.D., Andreassian, V. (2013). Environmental Modelling and Software 40, 1-20.

Benson, M., Coubrough, L. Millner, I., and R. van Voorthuysen (2012). Nutrient management approaches for the Tukituki catchment. Hawkes Bay Regional Council, Report WI 12/05, 40pp.

Clothier B. (2008). Statement of evidence by Brent Clothier. Environment Court evidence. Regional Plan Variation 5 ("RPV5") to the Proposed Waikato Regional Plan. 15p.

Dewes, A. (2013). Statement of evidence on behalf of Nelson/Malborough, North Canterbury and Central South Island Fish and Game Councils.

Dewes, A., (2015). Economic resilience and environmental performance of dairy farms in the upper Waikato region. University of Waikato Masterate thesis. http://researchcommons.waikato.ac.nz/handle/10289/9220

Dowbert vs Merrell Dow Pharmaceuticals, Inc. (1993). https://supreme.justia.com/cases/federal/us/509/579/

Fenton, T., and L. Lilburne (2009), Overview of catchment scale nutrient modelling in New Zealand. Outcomes from Workshop Wellington, July 2009. 45p

Forret, J. (1998). Scientific Evidence and Environmental Litigation in New Zealand. New Zealand Journal of Environmental Law. 39-62.

Ledgard, S.F. (2009). Section 43A report on behalf of Horizons regional Council Concerning Water Quality.

Mackay, A., Power, I., Green, S., and B. Clothier. (2012). Comparison of the nutrient outputs from the SPASMO and OVERSEER Models. Report prepared for Hawke's Bay Regional Council Ruataniwha Plains Water Storage Project. AgResearch Report.

Merz, S.K, and Centre for Groundwater Research and Training (2012). Waterlines Report Series No. 82.

Monaghan, (2010). Statement of resource consent applications to take and use water for irrigation in the MacKenzie Basin for Environment Canterbury. http://ecan.govt.nz/publications/

Park, S. (2014) Using OVERSEER within rules for the Lake Rotorua Catchment. Report prepared by Simon Park, Headway Ltd. For the Bay of Plenty Regional Council.

Parshotam, A., Wadhwa, S., and Mullan, B. 2009. Tauranga Harbour Sediment Study. Sediment Load Model Implementation and Validation. NIWA Client report HAM2009-007 prepared for Environment Bay of Plenty, March, 2009. 110pp.

Parshotam, A., Elliott, S., Shankar, U., and S. Wadhwa. (2013) National nutrient mapping using the CLUES model, NIWA Client report for Parliamentary Commissioner for the Environment, http://www.pce.parliament.nz/assets/Uploads/National-nutrient-mapping-using-the-CLUES-model.pdf

Parliamentary Commissioner for the Environment. (2013). Water Quality in New Zealand. Land use and Nutrient Pollution. http://www.pce.parliament.nz/assets/Uploads/PCE-Water-quality-land-use-webamended.pdf

Stephens, C., Graham, A.K. and J.M. Lyneis. (2005). System dynamics modelling in the legal arena: meeting the challenges of expert witness admissibility. System dynamics Review vol 21 (2): 95-122.

Vibart, R., Vogelerm, I., Cichota, R., and D. Horne. (2015). A comparison of APSIM and OVERSEER predictions of nitrogen leaching from a well-drained soil under a dairy farm. In: Moving farm systems to improved attenuation. (Eds L.D. Currie and L.L Burkitt). Occasional Report No. 28. Fertilizer and Lime Research DM, Ledgard SF, Monaghan RM, Mcdowell R, Deklein CaM (2006) OVERSEER nutrient budget model Centre, Massey University, Palmerston North, New Zealand. 6pp.

Wheeler, D., Ledgard, S.F., Monoghan, R.M., McDowell, R. and C. DeKlein (2006). OVERSEER development - what it is, what it does. In: Implementing sustainable nutrient management strategies in agriculture. (Eds Currie LD, Hanly JA). Occasional Report No. 19. Fertiliser and Lime Research Centre, Massey University. Palmerston North, New Zealand, pp. 231-236.

Williams, R., Brown, H., Ford, R., Lilburne, L., Pinxterhuis, I., Robson, M., Snow, V., Taylor, K., T. von Pein, (2014). The matrix of good management: defending good management practices and associated nutrient losses across primary industries. In: Nutrient management for the farm, catchment and community. (Eds L.D. Currie and C L. Christensen). Occasional Report No. 27. Fertilizer and Lime Research Centre, Massey University, Palmerston North, New Zealand. 8 pp.

Woods, R., Elliott, S., Shankar, U., Bidwell, V., Harris, S., Wheeler, D., Clothier, B., Green, S., Hewitt, A., Gibb, R and Parfitt, R. (2006 a). The CLUES Project: Predicting the Effects of Land use on Water Quality - Stage II. Prepared for Ministry of Agriculture and Forestry by NIWA, Client Report: CHC2006-09. 